\title{
Vehicle Routing Problem (VRP) for courier service: A review
}

\author{
Citra Dewi Purnamasari, ${ }^{1, *}$ and Amelia Santoso ${ }^{1}$ \\ ${ }^{1}$ Departement of Industrial Engineering, University of Surabaya, 60293 Surabaya, Indonesia
}

\begin{abstract}
The internet development access is really very fast and change all aspects for life activities include buying and selling transactions of goods or services that can arrange online or also called e-commerce which courier service influence. The courier basic operational is logistics of a supply chain. Transportation is a vital component in logistics management because it becomes the largest cost component in its activities that is about $50-60 \%$ of the total logistics costs. The purpose of this study is to find out what kind of vehicle routing problem (VRP) is used for courier service so can be used as reference for further research. Collect and selection process found 40 science journals for analyse. There has been a lot of research about the shortest route problem for courier service or can also called city logistics with VRP which the optimum solution obtained with heuristic and metaheuristic algorithm. Result found VRP type often used for courier service are dynamic VRP (DVRP) and VRP with time window (VRPTW) or can merging both dynamic VRP with time window (DVRPTW).
\end{abstract}

\section{Introduction}

The internet development access is really very fast and change all aspects for life activities include buying and selling transactions of goods or services that can arrange online or also called e-commerce. Based on the 2016 Economic Census Data, Indonesia became one of the world's highest e-commerce growth countries around $17 \%$ in the last 10 years [1]. Increased, significant cost of goods delivery services specially for courier, which is $14-15 \%$ for Indonesia or issued Rp. 50 trillion based on data from the Association of Express Delivery Service Companies, Post and Logistics Indonesia (Asperindo) in the same year.

The courier basic operational is logistics of a supply chain. Transportation is a vital component in this logistics management because it becomes the largest cost component in its activities that is about $50-60 \%$ of the total logistics costs [2]. Transportation costs are measurable costs but difficult to control.

In addition to transportation costs, the timing of transportation activities is also an important issue where it is required to minimize the transport process time [3]. Therefore, several studies were conducted with the aim of minimizing transportation costs while shortening the transportation process time. Reduced transportation costs, price of products

\footnotetext{
* Corresponding author: a.citra.dp@gmail.com
} 
or services offered can also decrease and more easily compete with competitors. This is supported by a statement from Ravindran and Donald [4] that in order to improve sales results by providing competitive pricing to market, minimization of process costs from the supply chain must be minimized, one of which is transportation costs minimization.

Goetschalckx [2] states that cost of transportation broadly divided into two fixed costs and variable costs. Fixed costs are the routine costs incurred by the company with a fixed nominal each period so that the nature of these costs is independent. Examples of fixed transportation costs include, vehicle investment costs and vehicle administration. While the variable cost is the nominal cost depends on the transportation operation so called the dependent cost. Examples of variable transportation costs include fuel costs, employee salaries, maintenance and handling costs. It should be noted that the classification of transportation cost components depends on company policy. Of the two types of transportation costs, variable costs are more influential to the degree of overall transportation costs than their fixed costs [5].

Several studies have been developed related to the shortest route selection to minimize transportation variable costs. Lee and Ji [6] reviewed the most widely used method for finding the shortest route with the development of the Travelling Salesman Problem (TSP) model and the Vehicle Routing Problem (VRP). Both models development, the optimum solution is obtained by using heuristic and metaheuristic algorithms [7]. All TSP model development has been well indicated by getting the optimum solution, but it is still too simple to represent the real condition, because TSP does not have limited vehicle capacity and service time. While based on the real case of the courier process there are limit variables for its operational processes, such as vehicle capacity and delivery service operational time. Similarly, the number of vehicles used by the courier must be more than one. Therefore, this paper will only discuss about VRP which is more complex than TSP. Toth and Vigo stated that VRP for the shortest route determination can reduce the cost significantly around $5 \%-20 \%$ [8]. The purpose of this study is to find out what kind of VRP is used for courier service so can be used as reference for further research.

\subsection{Vehicle Routing Problem (VRP)}

VRP was first introduced by Dantzig and Ramser in 1959 [9], initially known as trucking dispatching problem, which discusses the shortest route determination of gasoline delivery to several gas stations using trucks. Then develop several types of VRP along with methods for determining the shortest route.

Goetschalckx [2] defines VRP as the problem of determining the shortest route from a vehicle that starts from one depot to multiple destinations to meet customer needs of $n$. Where the vehicle has a certain capacity, every vehicle starts from the depot and returns to the depot. Each customer can only be visited once.

The purpose of VRP is to meet the needs of every customer with minimal cost. The cost is proportional to the total distance travelled by all vehicles so the VRP determines the shortest distance. The following are some of the constraints or limits that must be met in the VRP:

a. The vehicle route starts from the depot and ends at the depot.

b. Each customer must be visited once with one vehicle.

c. Vehicles used are homogeneous with a certain capacity so that consumer demand on each route traversed should not exceed the capacity of the vehicle.

d. If the vehicle capacity has reached the limit, then the next consumer will be served by the next shift.

General purpose of VRP: 
a. Minimize the distance and costs associated with vehicle use.

b. Minimize the number of vehicles needed to service the demand of all consumers.

c. Balancing routes in terms of travel time and vehicle load.

d. Minimize services that are less satisfactory to consumers, such as delays in delivery.

From 1959 to 2014, several VRPs developed based on several factors as the focus of determining the optimum solution and the constraint. Here is the classification of VRP types, there are Capacitated VRP (CVRP), Time dependent VRP (TDVRP), Pickup and delivery problem VRP (TDPVRP), Multi depot VRP (MDVRP), Stochastic VRP (SVRP), Location routing problem (LRPVRP), Periodic VRP (PVRP), Dynamic VRP (DVRP), VRP with time window (VRPTW), Fleet size and mix VRP (FSMVRP), Multi-compartment VRP (MCVRP), Split delivery VRP (SPVRP), Fuzzy VRP (FVRP), Open VRP (OVRP), VRP with loading constraint (VRPLC), Multi echelon VRP (MEVRP), Green VRP (GVRP), and VRP in reverse logistics (VRPRL) [6].

\subsection{Courier Service}

Courier service is a domestic or overseas package delivery service, while the package can be either document or goods [10]. Seherhand courier flow where the package is collected from customer one then in consolidate delivery into courier operational vehicle after pass sort process then delivery to other customer. Courier service is required to be fast and accurate in the process so that by determining the shortest path it can contribute to improve the quality of courier service.

VRP for courier service is very important role and very complex. This is because the customer data associated with the routing process, the nature is changing every day. So, opportunity for the same route will be very rare. Similarly, the types of managed packages will various each day. This is what distinguishes VRP for courier problems with VRP for the delivery of goods of a manufacturing company or distributor. Therefore, it is very important to identify at the beginning the appropriate VRP method for the courier so that the shortest route determination solution is obtained by the optimum solution.

Pillac., Et al [11] states that courier service is an application of city logistics and is so dynamic that it uses Dynamic VRP for its shortest route determination. City logistics is the optimization process for logistics activities, especially transportation in urban areas that pay attention to conditions related to traffic conditions, energy saving and economic aspects [12].

\section{Methodology}

Beginning with the determination of research objectives and then collected data from several scientific journals in the period of 2000 to 2018 publishing current and English version related to VRP. Then the selection of data obtained to proceed to the analysis and conclusions. The selection criteria collection journal data, as follows.

\subsection{Based on search engine}

Science journals obtained by searching on the site https://scholar.google.com/ only and non-commercial value (free) in English version. It is based on easier access to get it because author hope can be used as inspiration for many people to read, learn and then implement it. 


\subsection{Based on keywords}

Keywords used for searching which focused for the writing purpose only, so results obtained are appropriate and can be directly analyzed. The selected science journals are journals containing keywords both in the title and keywords of abstract. Keywords guidance for selection are routing, courier, and city logistics.

\subsection{Based on publisher}

In addition of 2 points as above, the selection of the source journals based on the publisher. Selected mostly only a few publishers which already have good credibility in their scope. So, the data obtained from source journals is expected to be data from good research. The following journal publishers are used, as below :

- Elsevier Ltd

- $\quad$ Springer Link

- Taylor \& Francis

- Other internation journal publisher (IEEE, Informs, Growing Science Ltd, and Witpress)

\subsection{Based on publication year}

Guidelines for journals selection as a research source based on the publication year. Selected in 2000s until now. Actual journal obtained also from 2000s to 2018s with follow attention to 3 points as previous mentioned before. Author reason provide publishing journal restrictions for data collection refer to internet trends development in the courier sector.

In summary, the methodology in this paper can be systematically represented in the flowchart of Figure 1. 


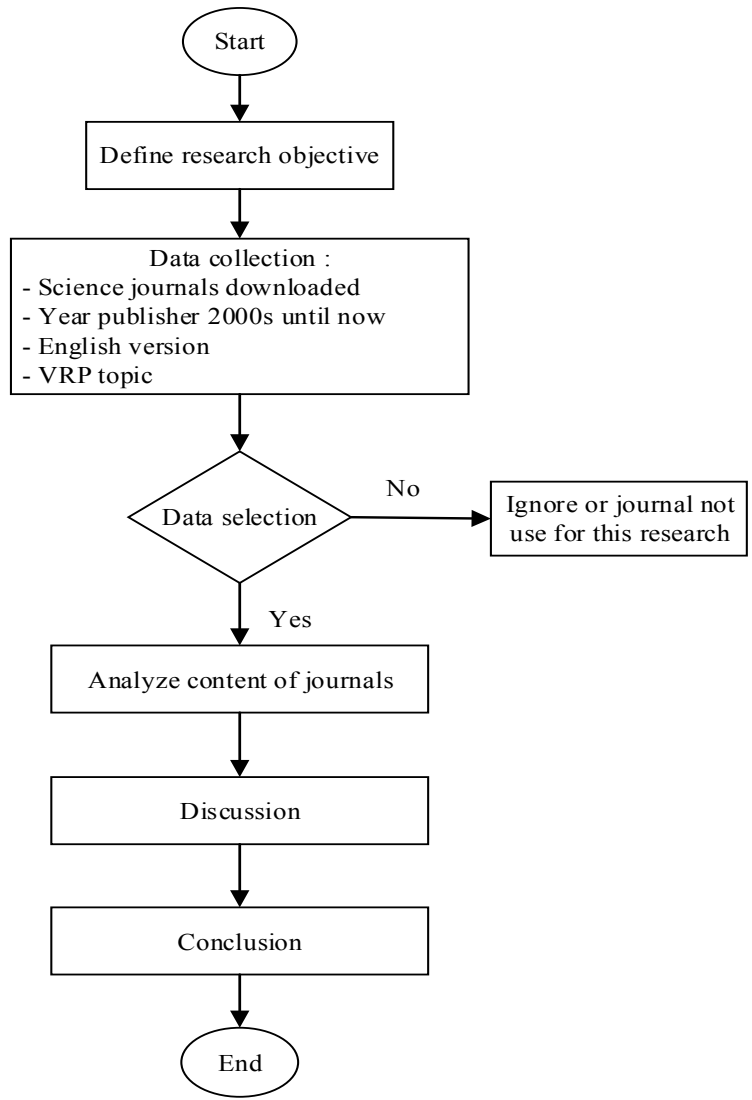

Fig. 1. Flowchart of Methodology

\section{Result and discussion}

Based on 4 point of journals selection for literature review source data, author obtained 40 science journals which summarized as follows:

Table 1. Classification Data Collection

\begin{tabular}{|c|c|c|}
\hline $\begin{array}{c}\text { Classification } \\
\text { data collection }\end{array}$ & Outcome & $\begin{array}{c}\text { Number of } \\
\text { Journals } \\
\text { founded }\end{array}$ \\
\hline $\begin{array}{c}\text { Keywords in } \\
\text { tittle and } \\
\text { abstract }\end{array}$ & routing & 32 \\
\cline { 2 - 3 } & courier & 12 \\
\cline { 2 - 3 } & City logistics & 12 \\
\cline { 2 - 3 } Publisher & Elsevier & 29 \\
\cline { 2 - 3 } & Springer Link & 5 \\
\cline { 2 - 3 } & Taylor \& & 2 \\
\cline { 2 - 3 } & Francis & 4 \\
\hline \multirow{4}{*}{ Publication year } & others & 2 \\
\cline { 2 - 3 } & 2000 & 2 \\
\cline { 2 - 3 } & 2002 & 1 \\
\cline { 2 - 3 } & 2003 & 2 \\
\cline { 2 - 3 } & 2004 & 1 \\
\hline
\end{tabular}




\begin{tabular}{|l|l|l|}
\hline \multirow{4}{*}{} & 2006 & 1 \\
\cline { 2 - 3 } & 2007 & 1 \\
\cline { 2 - 3 } & 2009 & 2 \\
\cline { 2 - 3 } & 2010 & 7 \\
\cline { 2 - 3 } & 2011 & 2 \\
\cline { 2 - 3 } & 2012 & 4 \\
\cline { 2 - 3 } & 2013 & 2 \\
\cline { 2 - 3 } & 2014 & 6 \\
\cline { 2 - 3 } & 2015 & 2 \\
\cline { 2 - 3 } & 2016 & 2 \\
\cline { 2 - 3 } & 2017 & 1 \\
\hline
\end{tabular}

Table 1 data show there have been several studies that discuss about courier routing problem which arranged into science journals and published during period 2000s-2018s in English version. Some journals content over than one keyword. The most science found journals with routing keywords, there are 32 journals. Keyword courier and city logistics found each 12 journals.

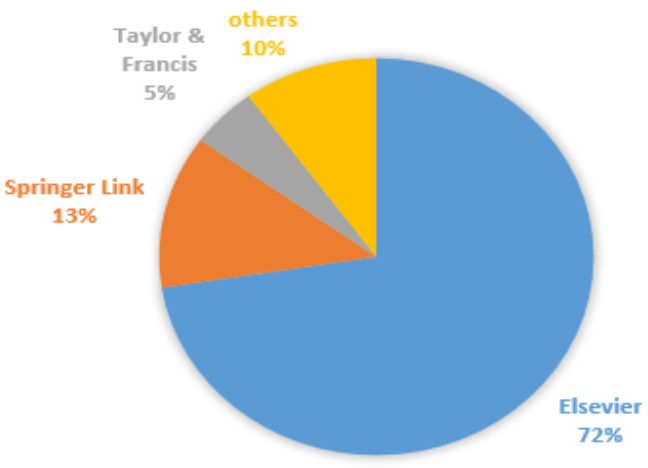

Fig. 2. Pie Diagram of Journal Publishers.

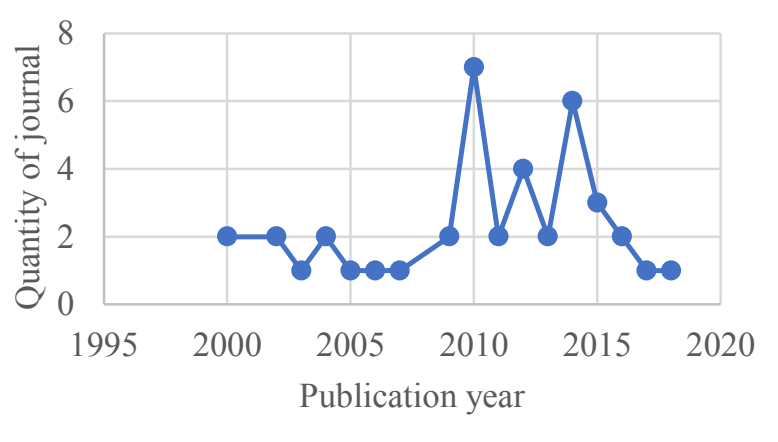

Fig. 3. Graphic of publication year journal

Refer to science journal publisher, the most frequent source journals in Elsevier Ltd publisher there are 29 journals or $72 \%$ of the total and almost all journals contain specified keywords. Thereafter, followed by Springer Link by $13 \%$, Taylor \& Francis in $5 \%$ or 2 journal. Other publisher consist 4 different publisher name each 1 journal so calculate as $10 \%$. Percentage data are presented in the following pie diagram on Figure 2.

Based on publisher year, 2000s until 2018s, found the most journal in 2010 that is 7 journal. From the graph of Figure 3 seen research concern about routing problem since 
2010 until now, where there are always journals published every year, it is in accordance with the development of courier industry in line with internet access development especially e-commerce $[13,19]$.

All source science journals refer to all keywords, obtained journal type as research journal in percentage of $67 \%$ for 27 journals. While the literature review journals only $33 \%$. Accordingly, it can be explain that a lot of research done by the previous author refer to many topics relevant with keywords. This journals data presented in Figure 4 below.

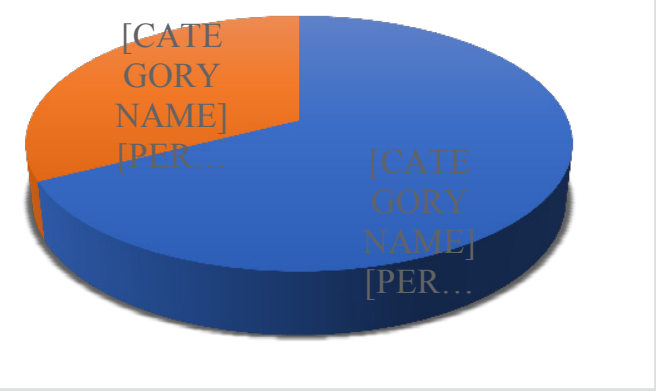

Fig. 4. Diagram pie of science journal type.

Research journals refer to VRPTW at most 6 journals, followed DVRP and DVRPTW each of 4 journals. VRP type data can be seen in table 2 .

Table 2. VRP type of research journals

\begin{tabular}{|c|c|c|}
\hline VRP type & $\begin{array}{l}\text { Journal } \\
\text { quantity }\end{array}$ & References \\
\hline Two Echelon & 3 & {$[41],[48],[50]$} \\
\hline Capacity, Dynamic & 1 & [31] \\
\hline $\begin{array}{l}\text { Capacity, Dynamic, } \\
\text { Pickup and Delivery }\end{array}$ & 1 & [32] \\
\hline Dynamic & 4 & $\begin{array}{l}{[10],[23],} \\
{[35],[36]}\end{array}$ \\
\hline $\begin{array}{l}\text { Dynamic, Pickup and } \\
\text { Delivery, Time Window }\end{array}$ & 3 & {$[22],[26],[39]$} \\
\hline Dynamic, Time Window & 4 & $\begin{array}{l}\text { [24], [25], } \\
{[33],[34]}\end{array}$ \\
\hline Multi Objective & 1 & [29] \\
\hline Mutli Trip & 1 & [30] \\
\hline Stochastic & 1 & [37] \\
\hline Time Window & 6 & $\begin{array}{l}{[13],[14],} \\
{[17],[21],} \\
{[27],[28]}\end{array}$ \\
\hline $\begin{array}{l}\text { Time Window, Pickup } \\
\text { and Delivery }\end{array}$ & 2 & {$[42],[44]$} \\
\hline Total & 27 & \\
\hline
\end{tabular}

There are 4 areas of correlation between journal keywords founded, illustrated in Figure 5. Area 1, correlation between routing and courier, found 8 journals discussed about research determining the shortest route of courier service with various methods of heuristic and metaheuristic for optimal solution and dominant refer to DVRP [10, 26, 31, 33] and VRPTW [17, 28, 33], also found research refer to multiobjective VRP [29]. Area 2, correlation between courier and city logistics, found only 1 literature review journal which discuss about impact courier service provide home delivery to city logistics alternative 
vehicles for routing problem [19]. Area 3, correlation between routing and city logistics, founded 5 research journals and 1 literature review journal [49]. For the 5 research journal discuss VRPTW [13], DVRP with time window (DVRPTW) for solve routing problem [24], pickup and delivery VRP with time window (TDPVRPTW) [42], the rest use two echelon VRP [41, 48]. Area 4, correlation between city logistics, courier, and routing which found 1 literature journal only which describe VRP for city logistics represented courier service activity [16].

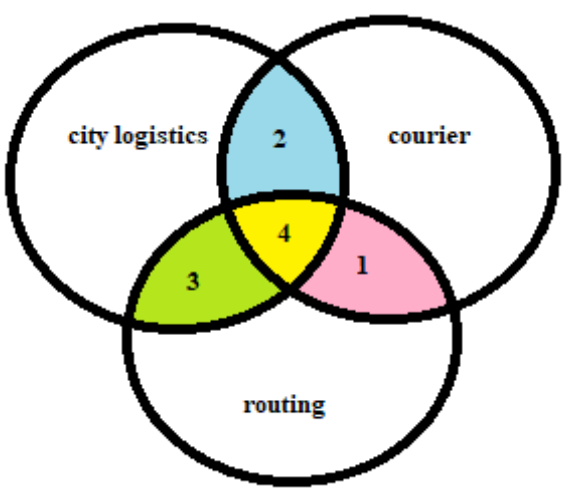

Fig. 5. Correlation between journals keywords.

\section{Conclusion}

There has been a lot of research about the shortest route problem for courier service or can also called city logistics with VRP which the optimum solution obtained with heuristic and metaheuristic algorithm. VRP type often used for courier service are DVRP and VRPTW or can merging both, DVRPTW. This is supported by keywords data which mapped in areas 1 and 3. Area Topic DVRP topic found 3 journals in area 1, topic VRPTW found 3 journals in area 1 and 1 journal in area 3. Then, DVRPTW found 1 journal in area 3. So, can be said that VRP for courier service almost important concern in constraint time window or operation time service and dynamic nature.

In the preparation of this paper there are some limitations that are expected to be attention for further research, there are:

- The source data only collect from science journals, there should be some other sources such as textbooks and newspapers.

- Science journals only collect from non commercial value (free) access, should be collect from payable science journals with relevant topics so that it can get more data for analyze.

\section{References}

1. K. Das, M. Gryseels, P. Sudhir, K.T . Than, Unlocking Indonesia's Digital Opportunity (McKinsey \& Company, Indonesia, 2016)

2. M. Goetschalckx, Supply Chain Engineering (Springer Science Business Media LLC, New York, 2011)

3. J.S.Y. Ho, D.O.L. Teik, F. Tiffany, L.F. Kok, T.Y. Teh, IPDER, 38, 113-117 (2012)

4. A.R. Ravindran, D.P. Warshing, Supply Chain Engineering Model and Application (CRC Press, New York, 2013)

5. N. Jozefowiez, F. Semet, E.G. Talbi, Eur J. O. R 189, 293-309 (2008) 
6. T.R. Lee, J.H. Ueng, Int J. P. D 29 (1999).

7. C. Lin, K.L. Choy, G.T.S. Ho, S.H. Chung, H.Y. Lam, Exp Sys 41, 646-657 (2014)

8. P. Toth, D. Vigo, The vehicle routing problem (SIAM, USA, 2002).

9. G.B. Dantzig, J.H. Ramser, TTDP, 6, 80-92 (1959)

10. C. Lin, K.L. Choy, G.T.S. Ho, H.Y. Lam, G.K.H. Pang, K.S.Chin, Exp Sys 41, 6917$6933(2014)$

11. V. Pillac, M. Gendreau, C. Gueret, A.L. Medalia, Eur J. O. R 225, 1-11 (2013).

12. E. Taniguchi, Pro S. B. S 151, 310-317 (2014)

13. G. Perboli, R. Tadei, Pro S. B. S 36, 639-646 (2010)

14. J.A.V. Lopez, A.B.P. Duenas, R.J.L. Ruiz, S.M. Cordoba, Pro S. B. S 160, 577-586 (2014)

15. G. Kim, Y.S. Ong, C.K. Heng, P.S. Tan, N.A. Zhang, IEEE 16 (2015)

16. D. Cattaruzza, N. Absi, D. Feillet, J.G. Feliu, Euro J 6, 51-79 (2017)

17. T.S. Chang, H.M. Yen, Eur J. O. R 223, 489-498 (2012)

18. R. Ducret, Res T. B. M 11, 15-22 (2014)

19. J. Visser, T. Nemoto, M. Browne, Pro S. B. S 125, 15-27 (2014)

20. G. Ghiani, F. Guerriero, G. Laporte, R. Musmanno, Eur J. O. B. S 151, 1-11 (2003)

21. W.C.V. Vasquez, E.R.L. Santana, G.A.M. Giraldo, WEA 141-152 (2016)

22. A. Slater, Int J. T. M 1, 29-40 (2002)

23. S. Lorini, J.Y. Potvin, N. Zufferey, Comp O. R 38, 1086-1090

24. E. Taniguchi, H. Shimamoto, Trans R 12, 235-250 (2004)

25. R.M. Branchini, V.A. Armentano, A. Lokketangen, Comp O. R 36, 2955-2968 (2009)

26. G. Ghiani, E. Manni, A. Quaranta, C. Triki, Trans R 45, 96-106 (2009)

27. I. Sungur, Y. Ren, F. Ordonez, M. Dessouky, Trans S 44, 193-205 (2010)

28. E.L. Santana, W.C.R Vasquez, G.M. Giraldo, Int J. I. E. C 9, 369-396 (2018)

29. J. Janssens, J.V.D. Bergh, K. Sorensen, D. Cattrysse, Eur J. O. R 242, 222-231 (2014)

30. C. Wang, M. Dessouky, INFOR, 53 (2015)

31. C.J. Malmborg, AMM, 24, 315-325 (2000)

32. S. Yan, J.R.Lin, C.W. Lai, Trans R 53, 34-48 (2013)

33. E. Angelelli, R. Mansini, M.G. Speranza, D. L 544, 87-103 (2005)

34. J.Y. Potvin, Y. Xu, I. Benyahia, Comp O. R 33, 1129-1137 (2006)

35. A. Larsen, O. Madsen, M. Solomon, Jour O. R 53, 637-646 (2002)

36. A. Polimeni, A. Vitetta, U. T 19, 823 (2013)

37. G. Shanmugam, P. Ganesan, P.T. Vanathi, Jour C. S 7, 533-542 (2011)

38. U. Ritzinger, J. Puchinger, R.F. Hartl, Int J. P. R 54 (2016)

39. S.M. Minic, R. Krishnamurti, G. Laporte, Trans R 38, 669-685 (2004)

40. G. Berbeglia, J.F. Cordeau, G. Laporte, Eur J. O. R 202, 8-15 (2010)

41. V.C. Hemmelmayr, J.F. Cordeau, T.G. Crainic, Comp O. R 39, 3215-3228 (2012)

42. J. Barcelo, H. Grzybowska, S. Pardo, D. F. M, (2007)

43. J.F. Ehmke, D.C Mattfeld, Pro S. B. S 39, 622-632 (2012)

44. E. Taniguchi, T. Yamada, Y. Kakimoto, IFAC 9, 33-38 (2000)

45. F. Russo, A. Comi, Pro S. B. S 2, 63355-6365 (2010)

46. A. Benjelloun, T.G. Crainic, Y. Bigras, Pro S. B. S 2, 6217-6228 (2010)

47. N. Anand, H. Quak, R.V. Duin, L. Tavasszy, Pro S. B. S 39, 101-115 (2010)

48. T.G.Crainic, G. Perboli, S. Mancini, R. Tadei, Pro S. B. S 2, 5944-5955 (2010)

49. P.O. Grob, M.W. Ulmer, J.F. Ehmke, D.C. Mattfeld, Trans R. P 10, 652-661 (2015)

50. G. Perboli, R. Tadei, ENDM 36, 639-646 (2010) 